\title{
A Research on Job Burnout of Archives Management Personnel in Colleges and Universities
}

\author{
Xiaohui Dai \\ Comprehensive Document Room, Taishan University, Tai'an 271021, China
}

\begin{abstract}
Keywords: colleges and universities, archives management personnel, job burnout, emotional exhaustion, cynicism, reduced personal accomplishment
\end{abstract}

\begin{abstract}
The questionnaire method, statistical method and interviewing method are mainly used for a research on job burnout conditions of archives management personnel in colleges and universities. According to the research results, job burnout is an objective issue for archives management personnel in colleges and universities. Job burnout of archives management personnel in colleges and universities is characterized with higher occurrence rate of males than females and higher occurrence rate of personnel with low titles and low administrative levels than personnel with high titles and high administrative levels. Emotional exhaustion and reduced personal accomplishment of personnel with long years of working (more than 10 years) are slighter than that of personnel with short years of working (less than 10 years). However, cynicism and job burnout of personnel with intermediate years of working (5-10 years) are more serious than that of personnel with other years of working.
\end{abstract}

\section{Introduction}

Archives management is served as important element works in colleges and universities, which plays a significant role in guaranteeing and promoting the development of teaching and management works in colleges and universities. Archives management in colleges and universities is complicated, tedious and relatively boring, which has higher professional requirements and psychological requirements for workers. Workers are the most active forces in archives management. Moreover, they are plan makers, organizers, controllers and executors of archives management, playing subject dynamic roles and having direct effects on the quality of archives management. With the development of informatization and systematic works, archives management in colleges and universities put higher and higher requirements for workers. With sharply increasing number of students in colleges and universities and related materials necessary for filing, the workload of workers also keeps continuously increasing. According to relevant researches, archives management workers in colleges and universities are engaged in obvious job burnout ${ }^{[1]}$. Colleges and universities must attach great importance to this phenomenon. For relevant researches on job burnout of archives management personnel in colleges and universities, however, the quantity is insufficient, the quality is not high, the research depth is inadequate and the research scientificity is not enough. Therefore, it is quite necessary and urgent for the research on job burnout of archives management personnel in colleges and universities.

\section{Subjects and Methods of Research}

Subjects of research: 45 archives management persons from a university in Shandong Province and another 9 colleges and universities are selected as subjects of research.

Methods of Research

Documentation method: relatively detailed research materials are obtained by referring to documents related to this research on the China Journal Net.

Interviewing method: some experts, archives management personnel and leaders are interviewed to obtain important data.

Questionnaire method: MBI-GS scale prepared by Shi Kan and Li Chaoping is adopted. This scale includes three parts: emotional exhaustion, cynicism and reduced personal accomplishment. The emotional exhaustion scale includes 5 questions, the cynicism scale includes 4questions, and 
the reduced personal accomplishment scale includes 6 questions. In total, there are 15 questions in the questionnaire. Likert 7-point rating scale is applied in this scale. 0 stands for "never", 6 stands for "quite frequent", and 3 stands for intermediate value ${ }^{[2}$. Totally, 45 questionnaires are distributed and 36 effective ones are recovered. The effective recovery rate is $80 \%$. In this survey, the internal consistency reliability of emotional exhaustion is 0.843 , that of cynicism is 0.805 and that of reduced personal accomplishment is 0.850 .

Statistical method: collected data is subject to statistics through spss16.0 for windows (confidence interval: 95\%; significance probability: $\mathrm{p}<0.05$ ). $\mathrm{t}$ checking and one-way analysis of variance are mainly performed.

\section{Results of Research}

Overall situation of job burnout of archives management personnel in colleges and universities

Table 1 Overall Situation of Job Burnout of Archives Management Personnel in Colleges and Universities

\begin{tabular}{cccrr}
\hline & $\mathrm{N}$ & Mean & Mean/Item & Std. Deviation \\
\hline Emotional Exhaustion & 36 & 17.722 & 3.544 & 1.056 \\
Cynicism & 36 & 13.778 & 3.444 & .856 \\
Reduced Personal Accomplishment & 36 & 20.222 & 3.370 & 1.043 \\
Job Burnout & 36 & 51.722 & 3.448 & .895 \\
\hline
\end{tabular}

According to the survey, an objective existence of job burnout is found in archives management personnel in colleges and universities, presenting in data: total scores of job burnout are 51.722. Average scores of the project are 3.448. The Likert 7-point scale from 0-6 scores is adopted and 3 stands for an intermediate value. Generally speaking, therefore, archives management personnel in colleges and universities are engaged in job burnout. On the dimension of emotional exhaustion, scores of archives management personnel in colleges and universities are 17.222 and average scores of the project are 3.544. On the dimension of cynicism, scores of archives management personnel in colleges and universities are 13.778 and average scores of the project are 3.444 . On the dimension of reduced personal accomplishment, scores of archives management personnel in colleges and universities are 20.222 and average scores of the project are 3.370. According to relevant data, average scores of emotional exhaustion, cynicism and reduced personal accomplishment are all higher than 3 (intermediate value), indicating that job burnout exists in these three dimensions. Among the three dimensions, the dimension of emotional exhaustion is the most serious, followed by cynicism and reduced personal accomplishment.

Variation analysis on job burnout of archives management personnel in colleges and universities Archives management personnel in colleges and universities are a group composed of individuals in different sexes, titles, ranks and years of working. In this research, a survey is made upon the assumption that above differences will cause differences in job burnout of archives management personnel in colleges and universities.

Sex variation analysis on job burnout of archives management personnel in colleges and universities

Table 2 Sex Variation Analysis on Job Burnout of Archives Management Personnel in Colleges and Universities

\begin{tabular}{cccccc}
\hline & & $\mathrm{N}$ & Mean & Std. Deviation & Sig. (2-tailed) \\
\hline Emotional Exhaustion & Male & 9 & 19.333 & 5.573 & .066 \\
& Female & 27 & 16.111 & 4.562 & \\
Cynicism & Male & 9 & 14.556 & 3.329 & .176 \\
& Female & 27 & 13.000 & 3.430 & \\
\multirow{3}{*}{ Reduced Personal Accomplishment } & Male & 9 & 21.444 & 6.793 & .247 \\
\cline { 2 - 5 } Job Burnout & Female & 27 & 19.000 & 5.594 & \\
& Male & 9 & 55.333 & 14.067 & .108 \\
& Female & 27 & 48.111 & 12.073 & \\
\hline
\end{tabular}

According to Table 2, there is no remarkable sex difference for job burnout of archives 
management personnel in colleges and universities, mainly demonstrating in the fact that the sex difference significance probabilities of job burnout are all greater than 0.05 (i.e. $\mathrm{p}>0.05$ ) for three dimensions of emotional exhaustion, cynicism and reduced personal accomplishment. The emotional exhaustion difference probability $\mathrm{p}=0.066>0.05$; the cynicism difference probability $\mathrm{P}=0.176>0.05$; the reduced personal accomplishment difference probability $\mathrm{P}=0.247>0.05$; and the job burnout difference probability $\mathrm{P}=0.108>0.05$. However, an issue is also indicated in Table 2: the job burnout level of male archives management personnel is higher than that of female archives management personnel. Moreover, the greatest difference between male and female archives management personnel lies in the dimension of emotional exhaustion, followed by overall level of job burnout, cynicism and reduced personal accomplishment.

Title variation analysis on job burnout of archives management personnel in colleges and universities

Table 3 Title Variation Analysis on Job Burnout of Archives Management Personnel in Colleges and Universities

\begin{tabular}{|c|c|c|c|c|c|}
\hline & & $\mathrm{N}$ & Mean & $\begin{array}{c}\text { Std. } \\
\text { Deviation }\end{array}$ & $\begin{array}{c}\text { Sig. } \\
\text { (2-tailed) }\end{array}$ \\
\hline \multirow[b]{2}{*}{ Emotional Exhaustion } & \multirow{2}{*}{$\begin{array}{l}\text { Below middle level } \\
\text { Above deputy and } \\
\text { senior level }\end{array}$} & 20.000 & 20.800 & 4.629 & \multirow[t]{2}{*}{.000} \\
\hline & & 16.000 & 13.875 & 3.074 & \\
\hline \multirow[b]{2}{*}{ Cynicism } & \multirow{2}{*}{$\begin{array}{l}\text { Below middle level } \\
\text { Above deputy and } \\
\text { senior level }\end{array}$} & 20.000 & 15.300 & 3.672 & \multirow[t]{2}{*}{.001} \\
\hline & & 16.000 & 11.875 & 1.821 & \\
\hline \multirow{2}{*}{$\begin{array}{l}\text { Reduced Personal } \\
\text { Accomplishment }\end{array}$} & \multirow{2}{*}{$\begin{array}{l}\text { Below middle level } \\
\text { Above deputy and } \\
\text { senior level }\end{array}$} & 20.000 & 23.500 & 4.904 & \multirow[t]{2}{*}{.000} \\
\hline & & 16.000 & 16.125 & 5.353 & \\
\hline \multirow[b]{2}{*}{ Job Burnout } & \multirow{2}{*}{$\begin{array}{l}\text { Below middle level } \\
\text { Above deputy and } \\
\text { senior level }\end{array}$} & 20.000 & 59.600 & 11.546 & \multirow[t]{2}{*}{.000} \\
\hline & & 16.000 & 41.875 & 8.107 & \\
\hline
\end{tabular}

In this research, titles of archives management personnel in colleges and universities are divided into below middle level (including middle level) and above deputy and senior level (including deputy and senior). According to the research, remarkable title difference $(p<0.05)$ exists among archives management personnel in colleges and universities no matter in overall situation of job burnout or in emotional exhaustion, cynicism and reduced personal accomplishment. To be specific, total scores of job burnout are 59.600 for personnel below middle level and total scores of job burnout are 41.875 for personnel above deputy and senior level, $\mathrm{p}=0.000<0.05$. Total scores of emotional exhaustion are 20.000 for personnel below middle level and total scores of emotional exhaustion are 13.875 for personnel above deputy and senior level, $\mathrm{p}=0.000<0.05$. Total scores of cynicism are 15.300 for personnel below middle level and total scores of cynicism are 11.875 for personnel above deputy and senior level, $\mathrm{p}=0.001<0.05$. Total scores of reduced personal accomplishment are 23.500 for personnel below middle level and total scores of reduced personal accomplishment are 16.125 for personnel above deputy and senior level, $p=0.000<0.05$. Thus it can be seen that personnel below middle level are remarkably higher than personnel above deputy and senior level in terms of total scores of job burnout, emotional exhaustion, cynicism and reduced personal accomplishment.

Administrative level variation analysis on job burnout of archives management personnel in colleges and universities 
Table 4 Administrative Level Variation Analysis on Job Burnout of Archives Management Personnel in Colleges and Universities

\begin{tabular}{|c|c|c|c|c|c|}
\hline & & $\mathrm{N}$ & Mean & $\begin{array}{c}\text { Std. } \\
\text { Deviation }\end{array}$ & $\begin{array}{c}\text { Sig. } \\
\text { (2-tailed) }\end{array}$ \\
\hline \multirow{2}{*}{ Emotional Exhaustion } & $\begin{array}{l}\text { Below leading roles of } \\
\text { sections or equivalents }\end{array}$ & 24.000 & 20.333 & 4.341 & .000 \\
\hline & $\begin{array}{l}\text { Above assisting roles of } \\
\text { divisions or equivalents }\end{array}$ & 12.000 & 12.500 & 2.153 & \\
\hline \multirow{2}{*}{ Cynicism } & $\begin{array}{l}\text { Below leading roles of } \\
\text { sections or equivalents }\end{array}$ & 24.000 & 14.667 & 3.784 & .005 \\
\hline & $\begin{array}{l}\text { Above assisting roles of } \\
\text { divisions or equivalents }\end{array}$ & 12.000 & 12.000 & 1.477 & \\
\hline \multirow{2}{*}{$\begin{array}{l}\text { Reduced Personal } \\
\text { Accomplishment }\end{array}$} & $\begin{array}{l}\text { Below leading roles of } \\
\text { sections or equivalents }\end{array}$ & 24.000 & 23.417 & 4.462 & .000 \\
\hline & $\begin{array}{l}\text { Above assisting roles of } \\
\text { divisions or equivalents }\end{array}$ & 12.000 & 13.833 & 4.019 & \\
\hline \multirow{2}{*}{ Job Burnout } & $\begin{array}{l}\text { Below leading roles of } \\
\text { sections or equivalents }\end{array}$ & 24.000 & 58.417 & 10.886 & .000 \\
\hline & $\begin{array}{l}\text { Above assisting roles of } \\
\text { divisions or equivalents }\end{array}$ & 12.000 & 38.333 & 5.710 & \\
\hline
\end{tabular}

In this research, administrative posts of archives management personnel in colleges and universities are divided into below leading roles of sections or equivalents (including leading roles of sections or equivalents) and above assisting roles of divisions or equivalents (including assisting roles of divisions or equivalents) for the convenience of comparative analysis. According to Table 4, remarkable administrative level difference $(\mathrm{p}<0.05)$ exists among archives management personnel in colleges and universities in terms of job burnout. To be specific, total scores of job burnout are 58.417 for personnel below leading roles of sections or equivalents and total scores of job burnout are 38.333 for personnel above assisting roles of divisions or equivalents, $p=0.000<0.05$. Scores of emotional exhaustion are 20.333 for personnel below leading roles of sections or equivalents and scores of emotional exhaustion are 12.500 for personnel above assisting roles of divisions or equivalents, $\mathrm{p}=0.000<0.05$. Score of cynicism are 14.667 for personnel below leading roles of sections or equivalents and scores of cynicism are 12.000 for personnel above assisting roles of divisions or equivalents, $\mathrm{p}=0.005<0.05$. Score of reduced personal accomplishment are 23.417 for personnel below leading roles of sections or equivalents and scores of reduced personal accomplishment are 13.833, $\mathrm{p}=0.000<0.05$. According to relevant data, personnel below leading roles of sections or equivalents are remarkably higher than personnel above assisting roles of divisions or equivalents in terms of total scores of job burnout, emotional exhaustion, cynicism and reduced personal accomplishment.

Years of working variation analysis on job burnout of archives management personnel in colleges and universities

In this research, years of working of archives management personnel in colleges and universities are divided into below 5 years, 5-10 years and above 10 years for survey and comparison. It is found after the one-way analysis of variance that remarkable working year difference exists among archives management personnel in colleges and universities in terms of total scores of job burnout, emotional exhaustion, cynicism and reduced personal accomplishment. Total scores of job burnout are $\mathrm{p}=0.000<0.05$. Total scores of emotional exhaustion are $\mathrm{p}=0.003<0.05$. Total scores of cynicism are $\mathrm{p}=0.000<0.05$. Total scores of reduced personal accomplishment are $\mathrm{p}=0.001<0.05$. For further analysis on differences in years of working, multiple analyses are made in this research, as shown in the following table. 
Table 5 Multiple Analysis on Working Year Difference in Job Burnout of Archives Management Personnel in Colleges and Universities

\begin{tabular}{|c|c|c|c|c|}
\hline Dependent Variable & $\begin{array}{l}\text { Years of } \\
\text { Working }\end{array}$ & $\begin{array}{l}\text { Years of } \\
\text { Working }\end{array}$ & $\begin{array}{c}\text { Mean } \\
\text { Difference }\end{array}$ & Sig. \\
\hline \multirow{2}{*}{ Emotional Exhaustion } & Above 10 years & 5-10 years & $-7.375(*)$ & .001 \\
\hline & \multirow{3}{*}{ 5-10 years } & Below 5 years & $-4.333(*)$ & .045 \\
\hline \multirow{2}{*}{ Cynicism } & & Below 5 years & $5.542(*)$ & .000 \\
\hline & & Above 10 years & $5.625(*)$ & .000 \\
\hline Reduced Personal & Above 10 years & Below 5 years & $-7.417(*)$ & .004 \\
\hline Accomplishment & \multirow{3}{*}{ 5-10 years } & $5-10$ years & $-9.000(*)$ & .000 \\
\hline \multirow{2}{*}{ Job Burnout } & & Below 5 years & $10.167(*)$ & .017 \\
\hline & & Above 10 years & $22.000(*)$ & .000 \\
\hline
\end{tabular}

According to Table 5, on the dimension of emotional exhaustion, scores of personnel with the working period below 5 years and as 5-10 years are higher than scores of personnel with the working period above 10 years. On the dimension of cynicism, scores of personnel with the working period as 5-10 years are higher than scores of personnel with the working period below 5 years and above 10 years. On the dimension of reduced personal accomplishment, scores of personnel with the working period below 5 years and as 5-10 years are higher than scores of personnel with the working period above 10 years. On the dimension of job burnout, scores of personnel with the working period as 5-10 years are higher than scores of personnel with the working period below 5 years and above 10 years.

\section{Discussion}

According to the research, job burnout is an objective issue existing among archives management personnel in colleges and universities. According to relevant results of this survey, average scores of job burnout questionnaires are 3.448 for archives management personnel in colleges and universities, higher than 3 (intermediate value). However, average scores of emotional exhaustion, cynicism and reduced personal accomplishment are between 3.370 and 3.544, indicating that the occurrence degree of job burnout is between "often" and "frequent" among archives management personnel in colleges and universities. There are probably the following causes for job burnout of archives management personnel in colleges and universities: heavy working strength, poor working environment, occupational reason of small personal development opportunity, social reason of the failure to obtain teaching, scientific research and attention of all sectors of society, laggard management thoughts, unsmooth operating mechanism, undefined responsibility partition and other internal system operating reasons as well as self reasons of archives management personnel such as self quality and psychology ${ }^{[3]}$.

There is no remarkable sex difference ( $\mathrm{p}>0.05$ ) in job burnout of archives management personnel in colleges and universities. According to the research, although there is no remarkable sex difference in job burnout of archives management personnel in colleges and universities, the burnout degree of male workers is higher than that of female workers. Due to the reason of job nature, archives are generally managed by female workers. The number of male workers is quite small. This is also found through the questionnaire survey. Archives management requires carefulness and patience. Moreover, workers should have good operational capabilities of logics. Generally speaking, females should be more competent for this job when compared with males due to physical and psychological characteristics of female. In a certain traditional inertial cognition, males are also reluctant to be engaged in archives management. This may be the reason for a higher job burnout degree of males than females.

According to the research, the burnout degree of workers below middle level is remarkably higher than that of workers above deputy and senior level in terms of total scores of job burnout, emotional exhaustion, cynicism and reduced personal accomplishment. The burnout situation of personnel below leading roles of sections or equivalents is remarkably higher than that of personnel 
above assisting roles of divisions or equivalents in terms of total scores of job burnout, emotional exhaustion, cynicism and reduced personal accomplishment. Archives management is boring, with slow social benefits, long-term efforts and heavy working strength. However, the issue of difficult promotion really exists for title and administrative level of archives management personnel at present, causing great psychological impacts to workers. For archives management personnel, if they fail to get promotion in title or administrative level for a long time, the probability of occurrence of their job burnout will increase. However, the probability of occurrence of personnel with higher titles and administrative levels should decrease accordingly.

In general, titles and administrative levels of archives management personnel with the working period above 10 years should be relatively high in colleges and universities. At the same time, their recognitions and understandings of archives management should be deeper through working for a long time. This can be used to interpret why their scores in emotional exhaustion degree and reduced personal accomplishment degree are lower than that of personnel with the working period below 5 years and as 5-10 years. Archives management personnel with the working period as 5-10 years are hard cores of archives management, who should be responsible for their superior leaders and for cultivation of new workers. At the same time, they are in a stage of to-be higher titles and administrative levels, so their psychological fluctuations are relatively great and their working strength, inner demands, psychological fluctuations and other aspects will be all higher than personnel with other period of working. Maybe, this is the reason why scores of cynicism and job burnout of personnel with the working period as 5-10 years are higher than that of personnel with the working period below 5 years and above 10 years.

\section{Conclusions}

Job burnout is an objective issue existing among archives management personnel in colleges and universities, to which great attention must be paid. For the job burnout of archives management personnel, males are higher than females and low titles \& low administrative levels are higher than high titles \& high administrative levels. Scores of emotional exhaustion and reduced personal accomplishment of personnel with long working period (above 10 years) are lower than that of personnel with the working period below 10 years. However, scores of cynicism and job burnout of personnel with intermediate working period (5-10 years) are higher than that of personnel with other period of working.

\section{References}

[1] Xu Ping, Xiong Caihong and Zhu Juanzhen, A Discussion on Causes and Countermeasures for Job Burnout of Achieves Management Personnel [J], Yunnan Archives;

[2] Li Chaoping and Shi Kan, The Influence of Distributive Justice and Procedural Justice on Job Burnout [J], Acta Psychologica Sinica, 2003, 35 (5): 677-684;

[3] Zheng Huiping, A Research on Job Burnout of Archives Management Personnel in Colleges and Universities [J], Journal of Jiaozuo University, 2009 (3): 0115-116. 